\title{
Análise Sociológica das Instituições Componentes do Arranjo Produtivo Local da Piscicultura no Município de Restinga Sêca no Estado do Rio Grande do Sul
}

Tainá Turri* João Vicente Ribeiro B. da Costa Lima*

\begin{abstract}
Resumo: Este artigo analisa o papel do ambiente institucional e o das instituições componentes do Arranjo Produtivo Local na região do COREDE Jacuí-Centro, no Rio Grande do Sul, mais particularmente das ações ocorridas no município de Restinga Sêca. Para tanto, baseada na chamada Nova Sociologia Econômica (Mark Granovetter) e na Teoria da Estruturação (Anthony Giddens) tenta-se compreender sociologicamente o APL da Piscicultura. Explora-se a definição do APL enquanto política pública. APLs são formados por um aglomerado de instituições que organizam um projeto para ser executado em torno de uma determinada atividade produtiva, onde existe uma possibilidade de interação local e geração de benefícios para os envolvidos, podendo gerar um aumento de renda e a possível melhora na qualidade de vida das comunidades envolvidas. No presente texto, o Arranjo Produtivo Local foi descrito e analisado a partir do entendimento (razões, interesses e projetos) de cada organização formal envolvida no Arranjo Produtivo Local. A partir dessa abordagem, pode-se avaliar a importância do ambiente institucional e organizacional no APL em questão no estudo. Os resultados da análise apontaram um APL com grandes dificuldades para ser executado.
\end{abstract}

Palavras-chave: Psicultura, Arranjo Produtivo Local, Ambiente Institucional.

Abstract: This article analyzes the role of institutional environment and its influence over the institutions that participate of the Pisciculture cluster at the region COREDE Jacuí-Centro, at Rio Grande do Sul, particularly the actions that took place in the city of Restinga Sêca. For that, based in the so called New Economic Sociology (Mark Granovetter) and in the Structural Theory (Anthony Giddens). It explores the definition of the Productive Local Arrangement as a public policy. The Cluster is formed by an agglomerate of institutions that organize a project to be executed concerned to a determined productive activity, that promotes a possibility for local interaction and a generation of benefits to the ones involved, which may lead to an income's increase and the possibility of life quality improvement to the communities involved. In the present work, the Cluster was described and analyzed from the understanding (reasons, interests and projects) from each formal organization involved in the Cluster. From this approach, the importance of the institutional environment can be assessed and the organization of the Cluster in question throughout this study. These analysis' results pointed to a Cluster with large difficulties to be executed.

Keywords: Fish Farm, Local Production Arrangement, Institutional Environment.

* Mestre em Ciências Sociais pelo Programa de Pós-Graduação em Ciências Sociais da Universidade Federal de Santa Maria.

* Professor do Programa de Pós-Graduação em Sociologia da Universidade Federal de Alagoas.

Latitude, vol. 3, n², pp. 107-122, 2009.

DOI: https://doi.org/10.28998/2179-5428.20090207 


\section{Introdução}

Este artigo analisa o conjunto de instituições que formam o ambiente institucional que abriga o Arranjo Produtivo Local (APL) da Piscicultura da região do Conselho Regional de Desenvolvimento do Jacuí-Centro (COREDE) ${ }^{1}$ : Agência Sul-Americana de Desenvolvimento (ADESUL), COREDE Jacuí-Centro, Associação Riograndense de Empreendimentos de Assistência Técnica e Extensão Rural (EMATER), Universidade Federal de Santa Maria e Universidade Luterana do Brasil (campus Cachoeira do Sul), e a Prefeitura de Restinga Sêca, que foi o município escolhido para análise desta pesquisa entre os sete municípios integrantes do COREDE Jacuí-Centro, que são Cachoeira do Sul, Cerro Branco, Novos Cabrais, Paraíso do Sul, Restinga Seca, São Sepé e Vila Nova do Sul).

A análise, compreendida pela ótica da sociologia econômica, que postula o evento econômico como socialmente constituído, centrou sua atenção sobre o conjunto difuso de interesses e práticas das instituições componentes do APL da piscicultura.

\section{Arranjo produtivo local, a nova sociologia econômica e a teoria da estruturação}

O conceito de Arranjo Produtivo Local (APL), na literatura brasileira, é caracterizado como uma política pública que visa ao desenvolvimento de atividades econômicas diversas, estruturando conjuntos de empresas e instituições interdependentes e com potencial para cooperação, fazendo que atores econômicos obtenham a capacitação e o desenvolvimento para consolidarem e expandirem suas atividades sobre novos mercados, gerando os bons efeitos sociais e econômicos. Um APL pode aglutinar esforços em todos os níveis executivos de poder (federal, estadual e municipal), além de reunir aparatos de instituições com recursos variados para a consecução dos objetivos do projeto. As ações de funcionamento de um APL iniciam com uma rigorosa preparação técnica do Governo Federal (de suas instituições participantes), passando por estágios intermediários de apreensão de demandas, conhecimento das particularidades locais até o estágio efetivo da implementação de ações que beneficiem indivíduos, empresas e atividades no plano local, fazendo assim, o funcionamento de um APL.

O projeto original do APL era a "Implantação do Arranjo Produtivo de Piscicultura nos Municípios do COREDE Jacuí-Centro do Estado do Rio Grande do Sul", que tinha como objetivo, a partir do contexto do desenvolvimento regional da região especificada para um APL de piscicultura, gerar trabalho e renda nos

1 Vide dissertação de mestrado "Análise sociológica das instituições componentes do Arranjo Produtivo Local da Piscicultura no Município de Restinga Sêca no Estado do Rio Grande do Sul” de Turri (2011), defendida no Programa de Pós-Graduação em Ciências Sociais da UFSM. 
municípios da região. Para tanto, era necessário um agrupamento de instituições públicas e privadas, além dos próprios pequenos produtores em vias de se tornarem também piscicultores, para prover as condições mínimas capazes de gerar os resultados esperados para a organização da produção, seu desenvolvimento técnico e gerencial, sob bases cooperativas eficientes para, ao final, propiciar a colocação de um produto competitivo no mercado - função principal desse APL.

Os municípios beneficiados com este APL da piscicultura apresentavam os típicos problemas deste território: pequenas propriedades familiares inviabilizadas técnica e gerencialmente, em dificuldades financeiras, baixa diversificação de atividades no meio rural e forte necessidade de alternativas para a geração de trabalho e renda.

As práticas rotinizadas do pequeno produtor/piscicultor estavam situadas em meio a uma dinâmica econômica rudimentar, mas de grande força emocional e de ativação de redes de solidariedade não-econômicas. A própria avaliação dos impactos sociais dessa política pública considerou a dimensão da competência dos agentes sociais para agir com eficiência e produtividade, no ambiente de competitividade onde estas políticas públicas são inseridas (FREITAS, 2011). No aspecto estritamente econômico, a racionalidade média do piscicultor mostrou-se limitada de maneira a não sustentar as boas práticas com as instituições participantes com vistas a obtenção dos ganhos econômicos estipulados. Os vínculos precários entre os piscicultores e as instituições não pode reter apenas o indivíduo piscicultor como o responsável pelos resultados incipientes obtidos. As ações dos parceiros institucionais constituem um quadro explicativo razoável para se entender o conjunto.

O desafio inicial do APL era a produção de peixe em escala regular a partir das expectativas de consumo com um padrão de qualidade pré-estabelecido ${ }^{2}$. Entretanto, a chance de êxito na criação de peixes na metade Sul requer a constituição de um complexo de instituições interrelacionadas que articule desde as instituições ligadas à pesquisa e ao planejamento, passando pela produção, até os estímulos mais apropriados ao mercado, com pretensões de que sejam geradas vantagens para todos os integrantes da cadeia.

Sobre a tese da imbricação social, desenvolvida por Mark Granovetter (1978), o APL pode ser visualizado também como uma rede. Para funcionar, esta Política Pública precisa de um encaixe mútuo entre seus participantes. É uma grande teia, onde cada integrante tem um papel a cumprir. No momento em que um estágio não funciona - esta rede deixa de funcionar.

Para Granovetter, as instituições econômicas estáveis começam por se desenvolver na base de modelos de atividade construídos ao redor de redes pessoais. Sua estrutura reflete a das redes em questão. Ainda para o autor, as instituições são conjuntos mais complexos de ações individuais que remetem frequentemente a ideia de que é assim que as coisas devem ser feitas. Na noção de instituição estão embutidas as dimensões de regularidade e de normatividade, sem que fique muito claro, no entanto, se a normatividade é de ordem moral ou técnica.

2 Conforme diagnóstico elaborado pela Agência Sul-americana de Desenvolvimento ADESUL. 
Além disso, as instituições são formadas da agregação de ações individuais - são construções sociais. As formas das instituições que compõem o APL da Piscicultura é também fortemente condicionada pelo conteúdo e pela estrutura das relações sociais nas quais a ação econômica está imbricada, ou seja, novamente, pela configuração das redes sociais.

$\mathrm{O}$ pequeno produtor inserido (e integrante do APL) precisa confiar em todas as escalas da política pública para entrar com a sua renda e a sua propriedade em um projeto com dimensões complexas e, pretende-se, melhore sua qualidade de vida. Por sua vez, A ADESUL (instituição que operacionaliza todas as ações do projeto) precisa que o Governo Federal libere o dinheiro para a política pública, e posteriormente, necessitará da aprovação do COREDE.

Por isto, Granovetter destaca o papel fundamental da confiança para que esta rede de imbricação estrutural funcione. $O$ indivíduo insere-se em relações mais afastadas que o colocam em contato com universos sociais distintos. Estas ações dos atores sociais são condicionadas pelo seu pertencimento a redes de relações interpessoais.

A análise desta rede do APL leva em conta as interações concretas entre indivíduos e grupos e as respostas alternativas que podem trazer a uma série de problemas-chave na teoria econômica. Esta rede social deveria facilitar a circulação de informações e assegurar a confiança ao limitar comportamentos oportunistas; o que não ocorreu no APL da Piscicultura.

Assim, criou-se para a execução desse APL (mais no planejamento do que na execução das rotinas do APL), uma base institucional que agregou as instituições como a EMATER - Associação Riograndense de Empreendimentos de Assistência Técnica e Extensão Rural - (na função de apoio técnico). Além disso, nessa estrutura as instituições de ensino superior (UFSM - Universidade Federal de Santa Maria - e ULBRA - Universidade Luterana do Brasil ) responsáveis, no planejamento do APL, pela pesquisa e desenvolvimento, no aprimoramento da criação e da carne de peixe, na criação de mecanismos de incremento do consumo, inserção no mercado externo, planejamento de marketing e gestão do negócio, de forma a garantir a competitividade do produto e sustentabilidade do empreendimento. $\mathrm{O}$ COREDE - Conselho Regional de Desenvolvimento - e também as Prefeituras integrantes do COREDE Jacuí-Centro.

A operação do APL pretendia a integração de toda a cadeia institucional incluída no arranjo produtivo: a produção, a transformação, a comercialização, a pesquisa e o desenvolvimento. Produtores, parceiros e cooperativas teriam que responder aos estímulos institucionais nos termos do planejamento do APL.

O Estado poderia atuar em vários níveis, seja na coordenação e na promoção de iniciativas sociais e empresariais, como a definição de implementação de linhas de crédito, como na concepção e implantação de programas de desenvolvimento mais contextualizados e, particularmente, nos municípios implicados, na operacionalização das compras públicas do peixe produzido para serem utilizados na merenda escolar desses municípios - por isso seu papel é fundamental. As compras públicas era um dos principais focos no planejamento do APL, pois poderia concretizar a venda efetiva do peixe produzido pelo APL. 
A abordagem da Nova Sociologia Econômica, da Teoria de Mark Granovetter (1990) permite a análise do APL da piscicultura para além de sua constituição econômica, mais precisamente das dimensões sociais formativas diversas e difusas. A Nova Sociologia Econômica empenha-se em identificar as formas de inserção social das ações econômicas e a influência das relações sociais nos resultados econômicos. Os enfoques são diversos e dentre eles destaca-se a "estrutura do mercado", visto como constituído de redes interpessoais. Para o autor, o mercado é o resultado não harmonioso e de constantes lutas. São essencialmente as relações pessoais, diretas ou indiretas, que permitem assegurar a confiança e evitar o oportunismo no mercado, sem que haja necessidade de uma coerção política externa.

Em sua análise dos grupos econômicos, Granovetter considera o papel do Estado fundamental. As regras administrativas e jurídicas influenciam obviamente a estrutura dos grupos econômicos, no que diz respeito à propriedade, às formas de autoridade e às relações com as instituições financeiras (no caso do APL, o Governo Federal como instituição financeira). O Estado aparece como um ator fundamental na regulação econômica (além de provedor financeiro, no caso de políticas públicas), cujo papel não consiste em apenas fazer respeitar as regras do jogo, estabelecido por e para os mais fortes - mas também inseri-se em todas as etapas, desde o planejamento até a conclusão da política pública (como forma também de verificação sobre como os recursos públicos foram administrados).

Granovetter afirma proposições que orientam a sua reflexão: a ação econômica é socialmente situada e as instituições econômicas são entendidas como construções sociais. A ação econômica é definida em termos de escolha entre meios raros ou como sendo orientada para a satisfação de necessidades definidas pelos indivíduos em situação de escassez (GRANOVETTER, 2000). Afirmar isso significa que, para Granovetter, os atores perseguem também objetivos sociais, como a sociabilidade, o reconhecimento, o status e o poder. Além disso, o problema da economia neoclássica para Granovetter reside menos numa psicologia ingênua do que no esquecimento das estruturas sociais (além da desconsideração em relação a todos os outros fatores não-economicos), ou seja, afirmar que a ação econômica é socialmente situada significa que os indivíduos não agem de maneira autônoma ${ }^{3}$, mas que suas ações estão imbricadas em sistemas concretos, contínuos, de relações sociais, ou seja, em redes sociais: é a tese da imbricação social das ações econômicas de Granovetter.

A lógica de concepção e funcionamento do APL é ilustrativa desta realidade da esfera econômica profundamente envolvida e orientada por processos e razões não-econômicas. O centro articulador das operações do APL, que fazem a ponte entre a política pública emanada de Brasília e as ações concretas dirigidas ao piscicultor, a saber, o COREDE Jacuí-Centro é uma entidade mais política e devotada aos problemas sociais de toda ordem do que propriamente uma entidade de natureza e operacionalidade econômica.

A forma assumida pelas instituições é fortemente condicionada pelo conteúdo e pela estrutura das relações sociais nas quais a ação econômica está

${ }^{3}$ A estrutura não afeta o indivíduo na formação de suas vontades e planos de ação. A estrutura, por sua vez, seria moldada pelos poderes inequívocos do indivíduo (GIDDENS, 2009). 
imbricada, ou seja, pela configuração das redes sociais. Granovetter afirma que, muitas vezes, as atividades econômicas nos países em desenvolvimento encontram-se freadas pela falta de confiança existente na sociedade. A confiança enraíza-se nas redes de relações interpessoais, assim sendo, a falta de confiança freia o desenvolvimento. $\mathrm{O}$ autor dá um exemplo, de um mesmo país, ou numa mesma região, diversos grupos sociais terão resultados econômicos diferenciados dependendo de sua estrutura social e a forma assumida pelas empresas dependerá também desta mesma estrutura social, o que implica na dependência das redes sociais. Nesse nível, a confiança é considerada como um elemento estruturante da relação entre as macroinstituições, como é o caso dos parceiros institucionais envolvidos no APL da piscicultura de Restinga Sêca ${ }^{4}$.

Granovetter volta à definição weberiana de ação econômica, mostrando que se trata de uma ação social, incluindo a dimensão conflituosa do mercado. Porém, é criticado por concentrar na ação racional com finalidade, sem citar as outras formas de ação social trabalhadas por Max Weber. A influência dos valores culturais é extremamente fundamental e não aparece em sua analise. As interações existentes entre a atividade econômica e o contexto jurídico e político-institucional, também não foi trabalhada por Granovetter, e é uma das preocupações fundamentais de Weber (RAUD-MATTEDI, 2008).

Anthony Giddens remete-nos à interação entre indivíduo e estrutura e sobre os processos e dinâmicas constituidores do indivíduo e da estrutura ${ }^{5}$. A base da teoria giddensiana está na produção e na reprodução da sociedade. Os indivíduos são os atores institucionais, os organismos parceiros que, a partir dos estímulos da coordenação COREDE Jacuí-Centro, operam segundo os objetivos do arranjo produtivo. A escolha por conjugar as proposições de Giddens com os postulados teóricos de Granovetter está em que a teoria de Giddens preocupa-se e articula mais a relação entre micro e macro estruturas da perspectiva da reprodução de uma ordem econômica, social e política em conformidade com certos aspectos do APL, especificamente, no foco de Giddens com a reprodução do sistema.

Em um nível analítico do APL, estima-se o quanto e de que maneira as relações sociais sustentadoras do APL da piscicultura conectam-se com os sistemas sociais no espaço e tempo; também que elementos normativos e alocativos são articulados no APL da piscicultura em uma conexão de elementos de sociabilidade

${ }^{4}$ Mas é importante lembrar que sua analise sociológica dos fenômenos econômicos, como rede, imbricação ou grupo econômico, é um marco - justamente por entender estes fenômenos econômicos como socialmente constituídos.

${ }^{5}$ As indagações feitas pela teoria da estruturação buscam os motivos pelos quais vivemos em sociedade, e das tensões e facilidades nas conexões entre o indivíduo e o meio social. Hoje, as concepções que predominam sobre as relações entre indivíduo e sociedade apontam que é a diferenciação das partes que gera a unidade do conjunto; porém, o contrário também é verdadeiro. Os indivíduos convencionam a vida em sociedade, mas a sociedade é, em múltiplos sentidos, quem dá origem ao indivíduo. Os indivíduos fazem a sociedade ao mesmo tempo em que é um indivíduo porque a sociedade assim o faz (GIDDENS, 2009). 
e de alcance econômico. As práticas econômicas e sociais do APL estruturam-se como rotinas que se conectam com o macro mundo. Em outro nível analítico - o que trata da inserção dos parceiros institucionais (EMATER, Universidades, Prefeituras, dentre outras) -, verifica-se um elo com o sistema. Não é mais o indivíduo piscicultor que age com base em suas boas razões, mas instituições, com funções particulares (prover recursos no campo da gestão da pequena empresa; transferir tecnologia para o pequeno piscicultor; dar o apoio político no âmbito das compras públicas no sentido de viabilizar um mercado seguro e mínimo), que se articula em níveis maiores de eficiência técnica, política e de gestão, passíveis de gerar ganhos maiores ou menores para o pequeno piscicultor.

A racionalidade do pequeno piscicultor é indicativa de seu ajustamento a uma ordem de realidade difusa que é o APL da piscicultura e materializa-se em práticas e rotinas que se constituem em sinalizações e disposições para interagir com os parceiros institucionais do arranjo produtivo. Os parceiros institucionais, por seu turno, deparam-se, na perspectiva da função e eficiência típicas, com este piscicultor e a sua racionalidade sobre o seu negócio (aqui, incluído o negócio Piscicultura, podendo ser assim caracterizado).

O tópico do poder constitui-se em um aspecto particular quando se pensa a realidade social complexa que permeia o APL da piscicultura. No contexto dos parceiros institucionais, o fenômeno do poder ocorre pelas características intrínsecas de cada entidade, de sua funcionalidade e das vantagens operacionais dadas e suas vinculações com outras esferas de poder. Pode-se chegar a aferir uma hierarquia entre as entidades pelo predomínio de algumas delas sobre as outras de um ponto de vista político (maior grau de articulação com instâncias políticas diversas, federal, estadual e municipal) e prático (de agir de forma operacional no interior do APL).

A desarticulação dos piscicultores é verificada pela ausência de organismos representativos e ativos no encaminhamento das demandas e das soluções do setor. $\mathrm{O}$ indivíduo piscicultor, ademais, manifesta suas porções de poder nas injunções da vida cotidiana, seja no plano estrito do APL, seja no âmbito de sua família e de sua comunidade. Sua interação com os parceiros institucionais não ilustra capacidades maiores de produzir resultados conforme lhe apraz.

\section{Arranjo produtivo local da piscicultura do corede jacuí-centro}

A data da proposta do APL remonta a junho de 2007. A proponente foi a Agência de Desenvolvimento de São Sepé (primeiro nome da ADESUL, que, hoje, é Agência Sul-americana de Desenvolvimento), enquanto que o COREDE (Conselho Regional de Desenvolvimento) consta no projeto como entidade interveniente, sendo que o período de duração do APL foi estimado em 24 meses.

O projeto do APL da piscicultura foi organizado e planejado pelo COREDE Jacuí-Centro e a execução ficaram a cargo da ADESUL 6 . O recurso destinado ao APL veio do Ministério da Integração Nacional, aprovado em duas parcelas de financiamento, perfazendo um total de $\mathrm{R} \$ 500.000$ reais.

\footnotetext{
${ }^{6}$ Uma Organização da Sociedade Civil de Interesse Pública — OSCIP.
} 
Os dados técnicos apresentados no projeto inicial do Arranjo Produtivo Local da Piscicultura informavam um valor total orçado em $R$ \$ 579.643,38 reais. O valor do financiamento advindo do Ministério da Integração Nacional era de R\$ $561.643,38$ reais, e ficou estabelecido que fossem recebidos em duas parcelas de igual valor - sendo a segunda parcela aprovada somente após prestação de contas referente à primeira parcela ${ }^{7}$.

Após aprovado o valor no Ministério da Integração Nacional, ficou a cargo do COREDE repassar esse valor a ADESUL para que essa instituição usasse o dinheiro a fim de desenvolver o APL da Piscicultura. Para esse dinheiro ser repassado a ADESUL eram realizadas assembléias com os municípios integrantes para aprovação do repasse do dinheiro para a ADESUL. No decorrer do APL, só foi realizada a primeira liberação, conforme descrição a seguir).

Foram contabilizados na projeção inicial do APL 685 produtores rurais como beneficiários diretos (todos dos sete municípios integrantes do COREDE). Os beneficiários indiretos, a mão de obra familiar, foi estimada em 3500 pessoas.

O custo estimado e planejado por propriedade agrícola que faz/faria parte do APL, foi de $\mathrm{R} \$ 846,19$ reais (especificadamente a construção de tanques). A estimativa de incremento de renda por propriedade foi de 1140 reais8.

O COREDE Jacuí-Centro, responsável pelo APL da piscicultura, é um dos personagens principais do arranjo técnico do arranjo. Ele é o mediador entre o Governo Federal, a ADESUL e todos os outros parceiros. As demandas legítimas dos cidadãos, cooperativas e demais representantes das comunidades para chegarem até a esfera federal precisam da legitimidade que o COREDE possui. Assim, todos se reportam ao COREDE. Os recursos vindos do Ministério da Integração Nacional, antes de repassados às instituições, são aprovados pelo COREDE em assembleia com todos os municípios envolvidos.

A ADESUL era a responsável pela elaboração do projeto e, tendo feito o estudo estatístico sobre sua viabilidade, o submeteu a Assembleia do COREDE, logrando aprovação. A partir do convênio firmado com o COREDE e os municípios integrantes, ficou sob responsabilidade da ADESUL a execução do APL, juntamente com as prefeituras. Isso significou a contratação de um técnico agrícola para assessorar os então "futuros piscicultores".

Mas antes das visitas do técnico agrícola, foram realizados seminários com esses produtores classificados ou dispostos a entrar no projeto 9 . No caso de Restinga Sêca, foram feitas reuniões para que os produtores, em questão, conhecessem o APL e, caso aceitassem participar, se inscrevessem para começar a receber o apoio técnico para construir a infraestrutura necessária para começar a produção do peixe para a piscicultura. Após isso, foram realizadas reuniões para

\footnotetext{
${ }^{7}$ A contrapartida financeira do projeto foi planejada em $\mathrm{R} \$ 18.000$ reais $(3,11 \%$ do valor total).

${ }^{8}$ Conforme dados da Agência de Desenvolvimento da Região Sul (ADESUL, 2007).

9 A ADESUL não prestou maiores esclarecimentos, nem documentais e nem na forma de depoimentos, sobre o processo (critérios, parâmetros, etc.) para escolha dos produtores apto a iniciar as atividades no âmbito do APL.
} 
aprendizagem sobre como produzir e como se caracterizava esse tipo de piscicultura proposta no APL. Essas reuniões aconteceram no Sindicato dos Trabalhadores Rurais de Restinga Sêca.

Após a adesão ao APL, o técnico contratado da ADESUL passou a visitar as propriedades cadastradas no projeto, dando suporte técnico. Enquanto isso, as prefeituras ficaram responsáveis pela construção dos tanques para receber o peixe.

No projeto original do APL da Piscicultura constam a Universidade Federal de Santa Maria (UFSM) e Universidade Luterana do Brasil (ULBRA) como integrantes do APL, para atuarem como base e fonte de pesquisa para um melhor aproveitamento da atividade da Piscicultura no APL.

Também consta no projeto inicial do Arranjo Produtivo Local, consta a EMATER como entidade parceira para o desenvolvimento do projeto. Antes disso, na formulação do projeto, a ADESUL utilizou-se das pesquisas já realizadas pela EMATER sobre a Piscicultura no Estado do Rio Grande do Sul - onde foi constatado que, entre os maiores entraves a piscicultura no Estado, se achava a falta de assistência técnica. Com o andamento do projeto, a função específica da EMATER era de fornecer assistência técnica complementar e extensiva nas propriedades.

A função específica das Prefeituras, dentro do projeto, mais precisamente, as suas Secretarias de Agricultura, foi a de, assim como a EMATER, fornecer apoio técnico, político e, principal e fundamentalmente, as prefeituras teriam que ser os primeiros compradores por meio do instrumento legal das compras públicas para destinação à alimentação escolar. $O$ fornecimento dos instrumentos para a construção dos tanques para receber os peixes também ficou a cargo das prefeituras municipais (o instrumento para a consecução do trabalho, no caso de Restinga Sêca, era uma escavadeira).

Durante as reuniões para cadastramento dos integrantes (produtores) beneficiados pelo APL, foi feita uma lista de ordem para recebimento das máquinas para construção dos tanques/açudes nas propriedades. Sendo assim, após esse cadastramento, o técnico da Secretaria de Agricultura do município levava a escavadeira até as propriedades e acompanhava a construção desses tanques.

Resumidamente essa é a descrição das atribuições a serem desenvolvidas pelas instituições componentes deste Arranjo Produtivo Local da Piscicultura e que serviu como ponto de partida para a análise da pesquisa até abril de 2011.

\section{Fatores econômicos e não-econômicos como percalços ao desenvolvimento do projeto}

A partir da analise do caso do município de Restinga Sêca no Arranjo Produtivo Local da Piscicultura e também a analise das instituições que participaram deste APL - investigadas aqui como objeto principal dessa pesquisa, considerando esses dois ambientes distintos - o ambiente institucional e o ambiente do pequeno agricultor, é que se detectou a grande lacuna entre essas duas realidades e também a diferença entre o planejamento inicial do APL e o que foi colocado realmente em prática, a partir desse planejamento inicial. 
O APL da Piscicultura nasceu com o foco dirigido ao pequeno agricultor familiar, em uma região do Rio Grande do Sul que, via de regra, tem um desempenho limitado e apresenta uma baixa eficiência econômica desses pequenos agricultores. Essas são características marcantes da região do Jacuí-Centro.

Considerando-se o capital cultural e social das famílias envolvidas, foi pensado um modo de mudar a difícil realidade dessas famílias. Pensou-se em formas de elevar o patamar de produção, comercialização para mudar essa realidade de atraso e baixa produtividade. Com essas características sociais e culturais, torna-se difícil imaginar uma mudança substantiva na mentabilidade dos agricultores envolvidos para ingressar nesse patamar de desenvolvimento planejado para o APL. Mesmo assim, projetavam-se uma melhora na renda já existente desses pequenos agricultores - que o APL pudesse trazer uma melhora substantiva quanto aos rendimentos econômicos.

“(...) O APL da piscicultura do Jacuí-Centro não lidou com situações complexas de aglomerações de pequenas empresas superespecializadas, com níveis de interação e cooperação efetivos, em uma dinâmica de aprendizagem e cooperação entre si, em média ou grande escala e com penetração real nos mercados mais competitivos e rentáveis.

Ainda assim, em bases menos complexas de interação, os resultados concretos reunidos mostram que todos os parceiros apresentaram um grau de articulação precário. A interação entre instituições de ensino e de crédito, respondendo aos estímulos (que, na realidade, não aconteceram) da Prefeitura é correspondente à ineficácia de instâncias como a associação de produtores e de cooperativas.

As partes inarticuladas do APL da piscicultura de Restinga Sêca são resultado dos entraves na harmonização das aglomerações e atores institucionais de natureza distintas econômica política e social. Vinculadas pelas atividades econômicas, as dimensões da política da sociedade e da economia, para o caso concreto do APL do Jacuí-Centro, em Restinga Sêca, apresentaram a realidade de uma esfera, em algum grau, em conflitos. "Os motivos políticos e a lógica da ação política rivalizavam com os objetivos maiores do projeto de um APL" (TURRI, p. 74, 2011).

Aconteceu com o APL da Piscicultura os caminhos tradicionais dos particularismos dos grupos de poder. Os piscicultores envolvidos não receberam todos o mesmo tratamento. A atenção e prioridade nas ações previstas para o APL, em algumas situações, foram implementadas de acordo com o grau de aproximação dos agricultores com os agentes políticos responsáveis pelo andamento do APL. Enquanto isso, os identificados como grupo de oposição ao 
partido situação da prefeitura de Restinga Sêca, reclamaram de falta de atenção (ou a inexistência de atenção) em suas propriedades.

Esse fato já explica os problemas pelos quais o planejamento inicial do APL enfrentou na sua realização pratica. A distância existente entre esse projeto inicial e a sua execução é abissal seus objetivos ficaram longe de serem concretizados.

A prefeitura é uma das instituições que deveria estar comprometida com os objetivos do APL, mas não é a única. Todas as instituições incluídas no projeto inicial deveriam ter exercido suas funções de acordo com o que foi estabelecido no planejamento do APL. Mais do que isso, o SEBRAE, importante instituição no que toca o assunto sobre Arranjos Produtivos Locais no Brasil (está envolvida em um grande número de APLs no Brasil, possuindo uma política de ação voltada para a execução de APLs, com vários APLs que obtiveram sucesso), não participou e não está nem incluída no APL da Piscicultura do COREDE Jacuí-Centro.

Algumas instituições vinculadas ao projeto, como as universidades UFSM e ULBRA passaram distante da realidade do projeto - o desenvolvimento, execução, prática do APL não chegou à etapa em que essas instituições realizam uma imersão nas formas do projeto original.

Os atores fundamentais para a implementação do APL da Piscicultura são o COREDE e a ADESUL. A prefeitura atua principalmente como instituição pública interessada e facilitadora para o incremento do APL (no caso de Restinga Sêca). Verificou-se uma enorme carência institucional onde o produtor não encontrou a assistência que lhe foi prometida na sua inserção no APL - o que fez com que atuasse baseando-se na improvisação para resolver os fazeres e problemas cotidianos da pratica da Piscicultura.

Em termos formais, o APL da piscicultura do COREDE - Jacuí-Centro, aqui estudado, no âmbito do município de Restinga Sêca, atendia às exigências abstratas mínimas: tinha um número significativo de empreendimentos não diretamente trabalhando com piscicultura, mas em condições reais e motivacionais para ingressar na atividade. Deve-se ainda destacar que o Rio Grande do Sul é pioneiro na cultura do associativismo e cooperativismo e estes instrumentos/organismos permeavam o universo do piscicultor de Restinga Sêca. Era visível aos gestores a possibilidade de operação de uma rede de conhecimento e de conexões entre os parceiros.

Diante dos resultados tímidos do tempo presente pode-se lembrar que os gestores, principalmente nos níveis federal e estadual, vislumbraram as dimensões das particularidades econômicas, sociais e políticas de um país diferenciado e complexo como o Brasil; de que modelos impostos de cima para baixo teriam pouquíssimas chances de êxito se descartassem a dimensão realmente "local" dos eventos. Os conceitos podiam e deveriam ser os mais genéricos, mas teriam que se aproximar do dado da realidade cotidiana, onde se inscreveriam a histórias de vida econômica do tipo humano, no caso, o piscicultor. Assim, foram feitos esforços para a flexibilização de modelos e metodologias, um exercício de crítica às taxonomias e aos indicadores econômicos convencionais discrepantes em relação à riqueza da diversidade cultural e econômica encontrada no país afora.

Os gestores, em nível federal e estadual, consideraram as particularidades econômicas sociais e políticas de um país diferenciado e complexo como o Brasil, isso diante dos resultados tímidos do tempo presente do APL. Modelos como o implantado para o APL da piscicultura, deveriam estar preocupados como fato de 
que modelos impostos de cima pra baixo teriam poucas chances de êxito ao descartar a dimensão "local" desse APL da Piscicultura. O planejamento deveria também ponderar uma maior aproximação do dado da realidade cotidiana em que se inscrevia a historia de vida econômica do tipo humano, o piscicultor. Este era um tópico importante para o tema último da melhoria da qualidade de vida destes pequenos produtores e suas famílias.

Os esforços para a flexibilização de modelos e metodologias foram feitos. Foram realizados fóruns regionais e locais para a implementação do APL; exercícios de criticas às taxonomias e aos indicadores econômicos convencionais discrepantes em relação à riqueza da diversidade cultural e econômica encontrada em um país tão abundantemente diversificado. Mesmo assim, o resultado (se é que se tenha chegado a algum, pois o APL da Piscicultura não saiu de algumas das primeiras ações da primeira fase) não chegou nem perto do esperado, considerando-se o intervalo de tempo da pesquisa do início de 2010 até a primeira metade de 2011.

“(...) Se, no plano mais abstrato e genérico, entendiam-se e refaziam-se os modelos pressupondo as realidades particulares; se, no plano intermediário (regional e local), os atores individuais e coletivos pressupunham, em suas falas, o enraizamento do particular como um valor absoluto; no plano local, o arranjo produtivo não logrou os ganhos esperados. Dessa forma, os obstáculos ao desenvolvimento do APL da piscicultura de Restinga Sêca, assim como nos outros municípios integrantes do APL, não têm correspondência com as ações das grandes burocracias indiferentes ao cotidiano das pessoas no mundo real" (TURRI, p. 77, 2011).

Apesar dessa dificuldade em combinar o modelo de desenvolvimento do APL com o que é enfrentado na realidade prática no cotidiano do APL da Piscicultura, os resultados reunidos e que indicam discrepâncias e desfuncionalidades, produzem um quadro que bem pode ajudar em estudos comparativos futuros, na detecção dos aspectos, tópicos e níveis institucionais que funcionaram mais ou menos, e que, finalmente, ajudem no desenvolvimento dessa política pública em termos mais gerais.

Um dos principais aspectos para os péssimos resultados apresentados pelo APL, sem dúvida, foi à ausência da assistência técnica "prometida" no planejamento do APL. Para trabalhar com a Piscicultura é imprescindível alcançar um nível mínimo de profissionalização ao menos para lidar com as etapas do cultivo (a criação, a construção e a manutenção dos açudes, a produção de peixes propriamente dita, a despesca, o controle de enfermidades aquáticas, a gestão dos recursos hídricos) e dos recursos para se inserir, nas outras etapas da cadeia produtiva do peixe (industrialização, comercialização e consumo).

O técnico da ADESUL designado para a função de auxiliar nesse ensino das técnicas da Piscicultura para o pequeno produtor teve um desempenho 
insuficiente para suprir a necessidade de agregar conhecimento técnico ao quadro mental do piscicultor no contexto das rotinas da piscicultura. Esta lacuna contribuiu para os baixos níveis de rentabilidade, um dos principais objetivos do APL. Novamente nesse aspecto da assistência técnica prestada ao pequeno agricultor verificou-se a diferença abissal entre o que foi proposto do planejamento do APL, com o que foi realmente executado no cotidiano do APL da Piscicultura.

Além da ADESUL, a prefeitura (no caso de Restinga Sêca) era uma entidade também responsável para o fornecimento da assistência técnica. E, contudo, a participação foi quase nula.

“De uma situação inicial promissora, com até três entidades com capacidade e comprometimento com a assistência técnica ao piscicultor, o que se viu foi, de um lado, a ação prática de quase apenas um ator institucional, no caso a ADESUL; ainda que a assistência tenha sido muito precária. A Prefeitura adotou uma postura quase de indiferença (apenas um técnico envolvido). O setor burocrático priorizou pouco o projeto e, assim sendo, deu pouca assistência técnica. A resultante de um conjunto de produtores produzindo peixe para um mercado incipiente (somente na Semana Santa) é a expressão da ausência técnica no monitoramento das ações. Tudo o que parecia favorável ao APL da piscicultura mostrou-se pífio: a escolha da carpa pela vantagem de ser uma espécie de rápido crescimento e de fácil adaptação no cultivo em tanques e alimentada por ração, em síntese, de fácil manejo, apresentou a incrível realidade da produção incipiente" (TURRI, p. 80, 2011).

A confiança mútua entre as instituições parceiras é mais formal do que efetiva, culminando com a saída da OSCIP ADESUL do projeto, sem a prestação de contas dos recursos recebidos na primeira etapa. Os resultados econômicos pífios obtidos retratam a desconfiança que, por sua vez, freou o desenvolvimento do projeto.

O ambiente institucional do APL da piscicultura do Jacuí-Centro contribuiu para os resultados econômicos abaixo das expectativas e de forma a afetar escassamente os projetos de futuro do pequeno produtor e piscicultor. As racionalidades de todos os atores envolvidos, incluindo o pequeno piscicultor, resultaram em um quadro de ineficiência. Os fins e os meios de cada ator institucional não se coadunaram em torno de meios e fins, procedimentos e rotinas convergentes.

“O pequeno piscicultor foi racional em boa medida. Sem ter os recursos técnicos, de gestão e a efetivação dos meios para industrializar e vender (o mercado cativo da compra pública), ele posicionou-se de maneira a não arriscar, a não fazer que o seu negócio ganhasse em escala por conta das incertezas. Sua ação ineficiente, ao final, guarda certa racionalidade. Sua limitação para lidar com recursos, tecnologias e outros instrumentos informa, 
quando muito, a sua falta de capacitação para operar, mas não irracionalidade.

As instituições parceiras também agiram em bases racionais. O COREDE, como entidade que acolhe e representa muitas outras instituições com interesses diversos, agiu nos limites formais em que convencionalmente atua. Objetivamente, viu-se que este padrão de ação do COREDE, de orientação política, mostrou-se deficiente para a consecução dos resultados finais ótimos para a piscicultura. Outros parceiros como EMATER, SEBRAE, Universidades, efetivamente não participaram do projeto. Este dado precisa ser entendido melhor tanto do ponto de vista da racionalidade do COREDE (que, obrigatoriamente, teria que fazer que essas instituições se somassem ao projeto) como se sabe que essas instituições de alguma forma tomaram conhecimento, mas não se envolveram" (TURRI, p. 82, 2011).

\section{Conclusão}

O APL da piscicultura mais se constituiu como parte de um jogo da política, com os atores mais ou menos dotados de recursos de poder, do que efetivamente um projeto que visava a resultados econômicos. Os parceiros operaram politicamente com os instrumentos à mão, em graus maiores ou menores de controle. O pequeno piscicultor mostrou-se o elo mais fraco dessa corrente política; sequer se constituía como grupo representado com uma prática que mostrasse uma interação maior entre seus membros para pelejar com outros atores institucionais.

Na situação que envolveu o APL da Piscicultura, o Estado, contrariando a imagem criada por setores da Sociedade, ou talvez até mesmo o senso-comum (imbuído de uma lógica coercitiva dos meios midiáticos da sociedade), ou ainda, a sua imagem historicamente estabelecida pelo neoliberalismo de atrapalhar o desenvolvimento, não atrapalhou ou emperrou o desenvolvimento deste APL. Pelo contrário, foi o fator decisivo para o seu início e funcionou em todas as partes que lhe foram cabíveis no planejamento deste APL. O seu papel fundamental, planejado pelas outras instituições envolvidas, foi a do Estado, como agente financiador - através do ministério da Integração Nacional.

Talvez lhe devesse caber uma maior participação, principalmente como agente fiscalizador do andamento desta política - para que a taxa de sucesso do APL alcançasse índices aceitáveis.

O que pode ser verificado como conclusão, foi que os integrantes da OSCIP envolvida, visualizaram um campo de atuação para a realização de um projeto como o APL na região do Jacuí-Centro do Rio Grande do Sul. Entretanto, o cenário socio-político apresentou dinâmicas socio-políticas na contramão das necessidades operacionais para a execução desta política pública, visível nas bases de 
desconfiança que atingiram as instituições envolvidas, e principalmente os pequenos agricultores envolvidos.

O atual estágio (durante a pesquisa realizada entre 2010 à 2011) do APL é o de estagnação. Foi decidido em assembleia do COREDE Jacuí-Centro e as prefeituras envolvidas - como resposta ao rompimento do contrato pela ADESUL - pela paralisação das atividades.

\section{Bibliografia}

AGÊNCIA SUL-AMERICANA DE DESENVOLVIMENTO. Portfólio de Atuação. São Sepé: ADESUL, 2009.

CONSELHO REGIONAL DE DESENVOLVIMENTO, COREDE. Implantação de Arranjo Produtivo de Piscicultura nos Municípios do COREDE JacuíCentro no Estado do Rio Grande do Sul. Cachoeira do Sul: ADESUL, 2007.

BALDISSEROTO, Bernardo. Piscicultura continental no Rio Grande do Sul: situação atual, problemas e perspectivas para o futuro. Revista Ciência Rural, Santa Maria, v.39, n.1, jan-fev, 2009.

ELSTER, Jon. Peças e engrenagens das Ciências Sociais. Rio de Janeiro: Relum e Dumará, 1994.

FREITAS, Tanise. Desenvolvimento humano e qualidade de vida: a racionalidade do

piscicultor do Arranjo Produtivo Local da Piscicultura no município de Restinga Seca

no Rio Grande do Sul. Dissertação de mestrado em Ciências Sociais (2011).

GIDDENS, Anthony. A constituição da Sociedade. São Paulo, Martins Fontes: 2009.

GRANOVETTER, Mark. Economic Action and Social Structure: The problem of Embeddedness. American Journal of Sociology. Volume 91, Nov. 1985.

Le marché autrement. Paris: Desclée de Brouwer, 2000.

O Problema da Imersão. Fórum - Sociologia Econômica - Ação Econômica e Estrutura Social. RAE - Eletrônica - volume 6, número 1, Artigo 5, janeiro.jjunho. 2007. Disponível em: http://www.fgvsp.br/institucional/biblioteca/pe/raeeletronica/SP000460366.pdf

The old and the new Economic Sociology: a history and an agenda. In: FRIEDLAND, R. E ROBERTSON, A.F. (Eds). Beyond the marketplace: rethinking economy and society. New York: Aldine de Gruyter, 1990.

. Threshold models of collective behavior. American Journal of Sociology, 1978. 
Análise Sociológica das Instituições Componentes do Arranjo Produtivo Local da Piscicultura no Município de Restinga Sêca no Estado do Rio Grande do Sul

LASTRES, Helena M. M.; CASSIOLATO, José E. (orgs.). Glossário de Arranjos e Sistemas Produtivos e Inovativos Locais. Rio de Janeiro: REDESIST, 2004. Disponível em: http://redesist.ie.ufrj.br/glossario1.php.

RAUD-MATTEDI, Cécile. Análise crítica da Sociologia Econômica de Mark Granovetter: os limites de uma leitura de mercado em termos de redes e imbricação. Revista Política \& Sociedade, número 6. UFSC: Florianópolis, 2005.

TURRI, Tainá. Análise Sociológica das instituições componentes do Arranjo Produtivo Local da Piscicultura no município de Restinga Sêca no Estado do Rio Grande do Sul. Dissertação de Mestrado. UFSM, 2011, 